\title{
Disruption of Lateral Efferent Pathways: Functional Changes in Auditory Evoked Responses
}

\author{
Colleen G. Le Prell, ${ }^{1}$ Susan E. Shore, ${ }^{1}$ Larry F. Hughes, ${ }^{2}$ and Sanford C. Bledsoe, Jr. ${ }^{1}$ \\ ${ }^{1}$ Kresge Hearing Research Institute, University of Michigan Medical School, Ann Arbor, MI 48109-0506, USA \\ ${ }^{2}$ Center for Alzheimer Disease and Related Disorders, Southern Illinois University Medical School, Springfield, IL 62702, USA
}

Received: 24 April 2002; Accepted: 13 November 2002; Online publication: 21 January 2003

\section{ABSTRACT}

The functional consequences of selectively lesioning the lateral olivocochlear efferent system in guinea pigs were studied. The lateral superior olive (LSO) contains the cell bodies of lateral olivocochlear neurons. Melittin, a cytotoxic chemical, was injected into the brain stem using stereotaxic coordinates and near-field evoked potentials to target the LSO. Brain stem histology revealed discrete damage to the LSO following the injections. Functional consequences of this damage were reflected in depressed amplitude of the compound action potential of the eighth nerve (CAP) following the lesion. Threshold sensitivity and N1 latencies were relatively unchanged. Onset adaptation of the cubic distortion product otoacoustic emission (DPOAE) was evident, suggesting a reasonably intact medial efferent system. The present results provide the first report of functional changes induced by isolated manipulation of the lateral efferent pathway. They also confirm the suggestion that changes in single-unit auditory nerve activity after cutting the olivocochlear bundle are probably a consequence of disrupting the more lateral of the two olivocochlear efferent pathways.

Keywords: lateral superior olive, guinea pig, olivocochlear, compound action potential, distortion product otoacoustic emission
Correspondence to: Colleen G. Le Prell - Department of Otolaryngology • Kresge Hearing Research Institute 1301 East Ann Street • University of Michigan - Ann Arbor, MI 48109-0506. Telephone: (734) 764-8532; fax: (734) 764-0014; email: colleeng@umich.edu

\section{INTRODUCTION}

The lateral and medial olivocochlear efferent systems can be distinguished using a number of criteria. These differences have been previously described and are reviewed here only briefly. First, the medial efferent pathway originates in medial, ventral, or periolivary zones (depending on the species), whereas the lateral efferent pathway originates in, or near, the lateral superior olive (LSO: for reviews, see Warr et al. 1986; Warr 1992). Second, whereas the medial efferent pathway is primarily a crossed system (approximately $60 \%-70 \%$ of the neurons cross the brain stem and innervate the ear contralateral to the site of origin), the lateral efferent pathway is predominantly uncrossed (for reviews, see Warr et al. 1986; Warr 1992). Third, the medial efferent neurons that project to the cochlea and synapse on the outer hair cells (OHCs) immunolabel positively for acetylcholine (ACh) and $\gamma$-aminobutyric acid (GABA; for reviews, see Eybalin 1993; Puel 1995; Le Prell et al. 2001). In contrast, the lateral efferent neurons synapse on the dendrites of the auditory nerve and, to a much lesser extent, the inner hair cells (IHCs). Immunocytochemical evidence suggests lateral efferent neurons contain a variety of neuroactive substances, including ACh, GABA, dopamine (DA), dynorphin (dyn), enkaphalin (enk), and calcitonin-gene-related peptide (CGRP; for reviews, see Eybalin 1993; Puel 1995; Le Prell et al. 2001).

Given anatomical and neurochemical differences, functional distinction of the lateral and medial efferent pathways would also be expected. However, a precise identification of lateral efferent function has not yet been possible. This is largely because surgical cuts of the efferent pathways disrupt only the crossed 
portion of the medial efferent pathway or both the medial and lateral pathways (e.g., Liberman 1991; Kujawa and Liberman 1997). Electrical stimulation paradigms, in which medial olivocochlear (MOC) neurons are electrically stimulated by an electrode placed at the floor of the fourth ventricle (e.g., Rajan 1988; Liberman 1991) or by an electrode near the site of MOC origin (i.e., Gifford and Guinan 1987), activate only portions of the medial efferent neurons.

Pharmacological manipulations initially appear to be useful in distinguishing lateral and medial efferent pathways. The glycinergic antagonist strychnine has been used to chemically block medial efferent function (e.g., Desmedt and Monaco 1961; Bobbin and Konishi 1974; Sridhar et al. 1995; Dolan et al. 1999). Recent molecular characterizations suggest that medial efferent modulation of OHC function occurs at heteromeric receptors composed of both $\alpha 9$ and $\alpha 10$ subunits (Elgoyhen et al. 2001). The distribution of $\alpha 9$ (and $\alpha 10$ ) receptors suggests the effects of strychnine will be limited to MOC blockade. Strychnine is also a potent antagonist at cholinergic $\alpha 7$ receptors isolated from retinal (Gotti et al. 1997) and hippocampal (Albuquerque et al. 1998; Matsubayashi et al. 1998) tissues; however, and the $\alpha 7$ receptor has been localized to type I spiral ganglion cells (Morley et al. 1998). Given that the predominant target for the LOC neurons is the type I spiral ganglion neurons, intracochlear strychnine may disrupt lateral efferent function. The functional significance of a potential strychnine blockade at $\alpha 9$ receptor subunits at the base of the IHCs (Elgoyhen et al. 1994; Park et al. 1997; Morley et al. 1998) is unclear.

In the present study we selectively destroyed neurons of the lateral olivocochlear system by injecting melittin into the LSO. Melittin is a cytotoxic extract of bee venom that disrupts the lipid bilayers of cells, thus altering cell membrane permeability and leading to intracellular ionic imbalance and cell death (Bechinger 1997; Kourie and Shorthouse 2000). The injection technique was modeled after a procedure that lesions the superior olivary complex (SOC) via injection of kainic acid (KA) into the brain stem. Those experiments were conducted in guinea pigs (Gardi and Bledsoe 1981; Bledsoe et al. 1990), rats (e.g., Li and Kelly 1992; Sally and Kelly 1992), ferrets (Rooney et al. 1991), and cats (Zaaroor and Starr 1991). One drawback to experiments in which KA is used to lesion the brain stem is that KA injection produces broad damage. Melittin offers an advantage over KA in that injection of melittin produces a discrete and well-localized lesion.

The LSO is the predominant nucleus of origin for the lateral efferent pathway in the guinea pig (Strutz and Bielenberg 1984; Robertson 1985; Aschoff and Ostwald 1987; Stopp 1990). In support of these findings, lesioning the LSO resulted in selective degeneration of the lateral efferent innervation of the cochlea as demonstrated by reduced labeling of synaptic vesicles in cochlear tissues that were immunolabeled with synaptophysin. The primary functional effect of lesioning the LSO was a reduction in CAP amplitude. This result supports and extends previous suggestions that the lateral efferent innervation of the cochlea modulates auditory nerve activity (Liberman 1990; Zheng et al. 1999).

\section{METHODS}

\section{Subjects}

Female guinea pigs (Elm Hill Breeding Labs, Chelmsford, MA) were used in these experiments. A number of animals were excluded based on elevation of thresholds prior to any experimental manipulation, evidence of middle ear infection at the time of euthanasia, or because the extent of damage to the LSO could not be assessed as portions of the SOC were missing. Only one animal died during recovery from the surgical brain stem lesion procedure. The remaining animals composed an acute electrophysiology group $(N=14)$ and a chronic electrophysiology group $(N=3)$. All animals underwent electrophysiological assessment of auditory function by measuring input-output functions for the sound-evoked wholenerve compound action potential (CAP) response.

Animals in the acute electrophysiology experiments underwent CAP testing 7 days after a lesion of the LSO $(N=4)$; control animals included animals that were not lesioned $(N=9)$ and an animal in which the lesion missed the LSO $(N=1)$. Data from 5 additional animals were excluded based on the criteria described above. For acute CAP recordings, a silver-wire ball electrode was placed on the round window from a postauricular surgical approach.

In the chronic electrophysiology experiments, guinea pigs were implanted with indwelling platinum-iridium ball electrodes that rested on the round window membrane. Beyond the second day postimplant, there was no evidence of time-related changes in CAP measures. These animals were allowed to recover for approximately one week, during which time baseline CAP measures were collected, and then the animals were lesioned. The melittin injections produced either targeted disruption of LSO $(N=3$; animals hereafter identified as "HIT1," "HIT2," and "HIT3") or no damage to the LSO ( $N=1$; animal hereafter identified as "MISS1"). We were unable to identify any damage within the auditory nuclei of animal MISS1, thus, we suspect the injection failed to deliver melittin into the neural tissue. We note that data from HIT3 were excluded based on evidence of 
an active middle ear infection at the time of euthanasia, and data from a fifth animal were excluded because portions of the SOC were missing.

All animals were maintained with free access to food (Purina guinea pig chow) and water. The animal care program was AALAC accredited. Husbandry met or exceeded all applicable standards, including the Guide for the Use and Care of Laboratory Animals, prepared by the National Research Council (1996). The Institutional Animal Care and Use Committee of the University of Michigan approved all animal care and testing protocols.

\section{Apparatus and procedures}

Brain stem lesions. Guinea pigs $(250-350 \mathrm{~g})$ were anesthetized (108 mg/kg ketamine, $14 \mathrm{mg} / \mathrm{kg}$ xylazine) and positioned in a Kopf (Model 1404) stereotaxic head holder (David Kopf Instruments, Tujunga, CA). The surface of the head was cleansed, and, using aseptic technique, the skull was surgically exposed and then thinned with a dental drill between Bregma and Lambda from approximately $1 \mathrm{~mm}$ left of midline to $3 \mathrm{~mm}$ right of midline. The thinned skull was removed using small bone rongeurs, exposing the midline blood vessels and the transverse sinus.

A pulled glass pipette (tip diameter approximately 20-50 $\mu \mathrm{m}$ ) was affixed to a $1.0 \mu \mathrm{l}$ glass microsyringe (model No. 700; Hamilton Company, Reno, NV). The syringe and tip were filled with melittin (Sigma Chemical St. Louis, MO). Prior to use, melittin was dissolved in normal Ringer solution $(145 \mathrm{mM} \mathrm{NaCl}$, $2.7 \mathrm{mM} \mathrm{KCl}, 2.0 \mathrm{mM} \mathrm{MgSO} 4,1.2 \mathrm{mM} \mathrm{CaCl}_{2}$, and 5.0 $\mathrm{mM}$ HEPES; $\mathrm{pH} 7.40$; osmolality = 280-285 mOsm) for a final concentration of $10 \mathrm{mM}$ melittin in solution $(\mathrm{pH} 7.0+0.5$; osmolality $=419 \mathrm{mOsm})$. The solution was aliquotted for storage at $0^{\circ} \mathrm{C}$ and warmed to room temperature prior to filling the microsyringe. Once filled with melittin, the microsyringe was positioned $1.2 \mathrm{~mm}$ posterior to the center of the auditory meatus (measured posterior to the center of the fixed earbar position), and $2 \mathrm{~mm}$ right of midline, at a $4^{\circ}$ (forward) angle off of vertical. The syringe, which was also used for evoked potential assessment as described by Gardi and Bledsoe (1981), was lowered through the cerebellum into the brain stem to an initial depth of $8 \mathrm{~mm}$.

Near-field sound-evoked potentials were assessed for right ear, left ear, and binaural stimulation at 8 $\mathrm{mm}$, and at depths proceeding in $0.5 \mathrm{~mm}$ increments. At each electrode depth, $10 \mathrm{kHz}$ tone pips $(0.5 \mathrm{~ms}$ rise-fall time; $70 \mathrm{~dB}-\mathrm{SPL})$ were used to generate neural responses. Acoustic stimuli were delivered via a $200 \Omega$ Beyer transducer (part number 102.938, type B4-31.05-00) housed in a custom-designed shielded case and tightly connected to hollow ear bars attached to the stereotaxic device. Sound pressure level calibrations were specific to each ear bar and were based on stimulus levels measured using a microphone (Bruel \& Kjaer type 4136 microphone, type 2619 preamp, type 2804 power supply) that was coupled to the ear bar at a distance of approximately 1 $\mathrm{mm}$. Coupling of the ear bar to the microphone during acoustic stimulus calibration was via vinyl tubing selected to approximate the guinea pig ear canal.

Acoustic stimuli were generated using TuckerDavis Technology (TDT) System II/System III hardware and SigGen 3.2 software (Tucker-Davis Technology, Alachua, FL). Evoked potentials were filtered $(300-3000 \mathrm{~Hz})$ and amplified (1000×) using locally constructed equipment and then digitized using the TDT BioSig 3.2 software package. BioSig 3.2 software was used to generate averaged evoked responses following 5 stimulus presentations $(2 / \mathrm{s})$. The depth of the LSO was identified by the maximum evoked response. In addition, the binaural interaction component was evaluated to determine when the sum of right ear or left ear stimulation was different than the effect of binaural stimulation (see Finlayson and Caspary 1989; Wada and Starr 1989; Ungan and Yagcioglu 2002).

Using the evoked potentials as a guide, injections of $10 \mathrm{mM}$ melittin $(0.2 \mu \mathrm{l})$ were made at depths ranging from 9 to $9.5 \mathrm{~mm}$. Melittin was injected via manually applied pressure delivered over a 1-min period. Following the injection of the cytotoxin, evoked potentials were reassessed. Approximately 2 min later, the syringe was removed from the brain stem, the skull was covered with Durelon carboxylate cement (ESPE, Seefeld, Germany), and the skin was sutured. Warmed saline $\left(38^{\circ} \mathrm{C}, 20 \mathrm{ml} / \mathrm{kg}\right)$ was injected subcutaneously at the conclusion of the surgical procedure. In addition, animals were treated with the antibiotic chloramphenicol $(30 \mathrm{mg} / \mathrm{kg}$, twice daily) to prevent postoperative infections.

Inner ear electrophysiology-acute procedure. Animals were anesthetized (108 $\mathrm{mg} / \mathrm{kg}$ ketamine, 14 $\mathrm{mg} / \mathrm{kg}$ xylazine), screened for healthy tympanic membranes and ear canals, and placed in a guinea pig head holder (SG-1, Narishige Group, East Meadow, NY). A thermostatically controlled heating pad was used to maintain body temperature at $37-38^{\circ} \mathrm{C}$. A right postauricular incision was made, and the bulla was carefully exposed and opened. A silver-wire ball electrode (diameter $=0.3-0.35 \mathrm{~mm}$ ) was placed gently on the round window and cemented in place.

Acoustic stimuli were delivered from the Beyer transducer, which was tightly connected to hollow ear bars that were fixed to the Narishige head holder. CAP input-output functions were determined for brief 
pure-tone stimuli (2-20 kHz; $2 \mathrm{kHz}$ increments) presented at levels ranging from 0 to $100 \mathrm{~dB}$ SPL $(5 \mathrm{~ms}$ tone pips, $0.5 \mathrm{~ms}$ rise-fall; $10 / \mathrm{s}$ ). Acoustic stimuli were generated using TDT System II/System III hardware and SigGen 3.2 software. Stimulus calibrations specific to the ear bars that fit the Narishige head holder were conducted as described above. Evoked potentials were filtered (300-3000 Hz) and amplified (1000×) using locally constructed equipment. BioSig 3.2 software was used to average 25 presentations within each frequency/level combination. Responses to $20 \mathrm{kHz} 100$ dBSPL stimuli were discarded because of substantial distortion of the acoustic signal.

Inner ear electrophysiology-chronic procedure. Animals were anesthetized (108 mg/kg ketamine, 14 $\mathrm{mg} / \mathrm{kg}$ xylazine), screened for tympanic membrane inflammation, positioned in the Narishigi head holder, and placed on a heating pad to maintain body temperature at $37-38^{\circ} \mathrm{C}$. Aseptic surgical procedures were used. From a right postauricular approach, the bulla was carefully exposed and opened and a platinum-iridium wire ball electrode (0.3-0.35 $\mathrm{mm}$ diameter) was placed gently on the round window and cemented in place at the bulla opening. The free end of the electrode, which had been soldered to a pin-based socket strip connector (Samtec Inc., New Albany, IN) and sterilized prior to the implant surgery, was cemented to the top of the skull using Jet Repair Acrylic (Lang Dental Manufacturing, Wheeling, IL). A ground wire was implanted into the muscles of the neck. Use of this two-pronged connector allowed CAP responses to be assessed within the same animal over long periods of time, including prelesion and postlesion.

Following the implant surgery, CAP responses were assessed. Acoustic stimuli were generated as described above. However, sounds were presented through a piece of plastic tubing inserted into the ear canal. Use of this tubing avoided trauma to the ear canal as a result of repeated placement into the headpositioning device. CAP input-output functions were determined in anesthetized animals as described above; however, for a subset of animals, testing was limited to $10 \mathrm{kHz}$. Stimulus calibrations specific to the plastic tubing were used during collection and summary of the data. Following injection of melittin into the brain stem, electrophysiological testing was conducted at various time points, including immediately, 1-day, and 1-week post lesion, as well as at weekly intervals extending to 17 weeks postlesion.

DPOAE testing. The lesioned animals in the chronic experiments underwent DPOAE testing at 1 and 9-weeks postlesion. The cubic distortion product was assessed. Testing was conducted in the contralateral ear as a control procedure, unless the tympanic membrane of the contralateral ear appeared cloudy, red, or otherwise irritated. A MatLab program was used to control stimulus generation (TDT hardware) and data collection. Two Beyer transducers were used to generate acoustic signals. Transducer output was tightly coupled to sound delivery ports in the microphone used to measure sound-evoked DPOAEs (Etymotic Research, Elk Grove Village, IL; ER-10B+ Low Noise Microphone). The microphone (gain $=40 \mathrm{~dB}$ ) was covered with an open-ended plastic tip to shield it from any wax in the ear canal and was placed inside the ear of the anesthetized animal using a microscope. The shielded microphone was placed near the tympanic membrane, which was inspected for inflammation or trauma before and after each DPOAE procedure.

During DPOAE testing, the primary tones were fixed at $8 \mathrm{kHz}(\mathrm{F} 1)$ and $9.6 \mathrm{kHz}(\mathrm{F} 2)$. Initially, F1 and F2 levels were 60-dB SPL; sound levels were adjusted until the cubic distortion product (2F1 - F2) was 10$15 \mathrm{~dB}$ above the noise floor. The level of $\mathrm{F} 2$ was then systematically decreased until it was $10 \mathrm{~dB}$ lower than that of F1. The level of F2 was increased to equal the level of $\mathrm{Fl}$ (as a test/retest control procedure), and then the level of $\mathrm{Fl}$ was decreased until it was $10 \mathrm{~dB}$ lower than that of F2. The level of Fl was increased to equal the level of F2 at the conclusion of the DPOAE testing. Responses to 25 stimulus presentations were collected and averaged at each sound level combination ( $50 \mathrm{~ms}$ duration, presentation rate $=1 / \mathrm{s}$ ).

Brain stem histology. At the conclusion of electrophysiological testing, most animals were anesthetized and euthanized via intracardiac perfusion of fixative [4\% paraformaldehyde, or $3 \%$ glutaraldehyde $+2 \%$ paraformaldehyde, in phosphate buffer $\left(\mathrm{PO}_{4}: 0.1\right.$ $\mathrm{M})$ ]. The brain stem was removed and placed in $4 \%$ paraformaldehyde for a minimum of $24 \mathrm{~h}$. The brain was then placed in a $30 \%$ sucrose solution for 24-48 $\mathrm{h}$, sectioned $(70 \mu \mathrm{m})$ using a freezing microtome, mounted on glass slides, and stained with cresyl violet. We note that the placement of the pipette in the brain stem transected the OCB in one guinea pig that was not included in this investigation. Because cresyl violet stain does not readily allow an evaluation of OCB integrity, processing of neural tissues was different for two animals (HIT2 and MISS1). Brain stem sections from these animals were labeled for acetylcholinesterase following Osen and Roth (1969; see also Liberman 1990). The animals were anesthetized and euthanized via intra cardiac perfusion of $10 \%$ formalin solution. The brains were removed, placed in $10 \%$ formalin solution overnight, and stored in PBS. The brains were later placed in a $5 \%$ sucrose solution for 3 days and then sectioned $(80 \mu \mathrm{m})$ using a freezing microtome.

All sections were viewed under a Leitz Laborlux Microscope, digitized using a Nikon Coolpix 990 


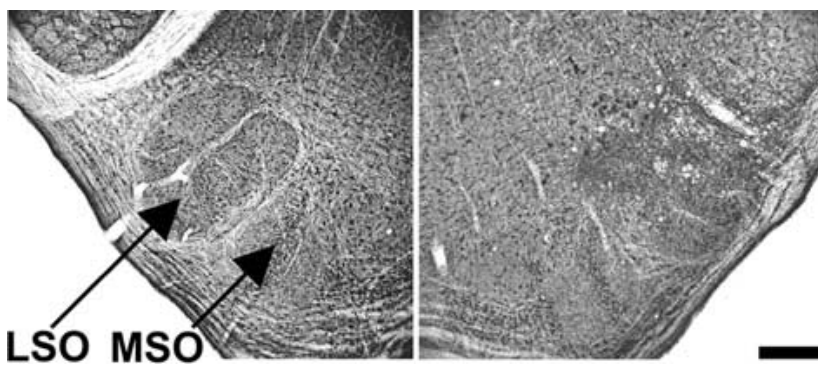

FIG. 1. Representative brain stem section from an acute test animal scored as an LSO hit. Left: Intact (control) side of brain stem. Both the U-shaped lateral superior olive (LSO) and the more medially located medial superior olive (MSO) are evident (see labeled arrows). Right: The experimental (cytotoxin-injected) side of the same brain stem as depicted in left panel. The lesion is centered over the LSO, with only the most ventromedial aspects of LSO appearing undamaged. The damage to the neural tissue does not extend to the MSO. Scale bar $=400 \mu \mathrm{m}$.

digital camera, and analyzed using Metamorph Imaging System (4.5a5, Universal Imaging Corporation, Downingtown, PA). Following treatment with cresyl violet label, the lesion appeared as a darkened area where glia and scar tissue invaded the healthy cell region (see Fig. 1). In contrast, in sections treated with acetylcholinesterase histochemistry, the lesion appeared as a loss of the brown neuropil staining. Brain stem sections were scored as hits when the lateral limb of LSO was completely disrupted and at least some portion of the medial limb was also damaged. When LSO was hit, the area of the undamaged cell bodies within LSO was measured on both sides of the brain stem (see Fig. 2). To measure undamaged area, regions containing intact cell bodies were circled and the area of the circle was calculated using Metamorph image analysis software.

Inner ear histology. After removal of the brain, the temporal bones were removed. They were dissected open at the round window and the apex and gently perfused with $4 \%$ paraformaldehyde in phosphate buffer $\left(\mathrm{PO}_{4}: 0.1 \mathrm{M}\right)$. Immunolabeling with antisynaptophysin mouse monoclonal antibody (1:10 dilution; IGN Pharmaceuticals, Inc., Aurora, $\mathrm{OH}$ ) was conducted using procedures modeled after those of Burgess et al. (1997). The tissues were then carefully dissected for surface preparations and mounted on glass slides or were dehydrated in graded alcohols and embedded in resin (Embed 812; Electron Microscopy Sciences). Synapse-specific labeling was observed in cochlear tissues from two animals that were perfused with $4 \%$ paraformaldehyde (see Fig. 3). Tissues from one animal were limited to the basal turn due to trauma associated with dissection; tissues from the second animal were available for all cochlear turns.

Lateral efferent innervation of the cochlea is not easily quantified because lateral efferents appear as

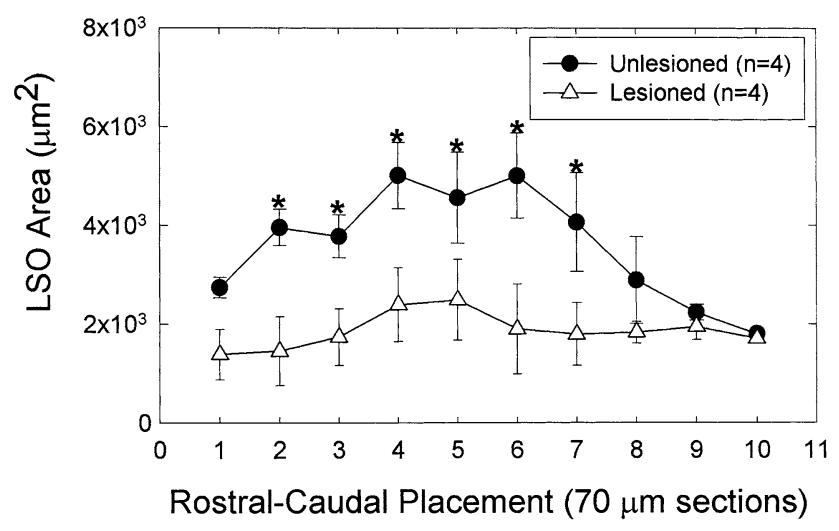

FIG. 2. Area of intact (undamaged) lateral superior olive (LSO) was measured following injection of a cytotoxin into the vicinity of LSO (e.g., "Lesioned"). Control comparisons were provided from measurements of LSO area in contralateral, uninjected LSO (e.g., "Unlesioned"). Section 1 was the most caudal section in which LSO appeared. Sections were sequentially numbered until LSO was no longer evident. Asterisks denote statistically reliable differences between lesioned and unlesioned sections ( $\left.p^{\prime} \mathrm{s}<0.05\right)$.

distinct puncta that range in size as well as amorphous bundles. Given that they cannot be readily counted, we quantified lateral efferent innervation by determining the surface area of the immunolabeled lateral efferents in the intact ear and in the ear for which lateral efferent innervation was expected to be disrupted (i.e., the ear ipsilateral to the brain stem lesion). Surface area was assessed across a $325 \mu \mathrm{m}$ segment from each cochlear turn in four sections of approximately $81 \mu \mathrm{m}$. Labeled area was measured using a sliding analysis window (area $=974 \mu \mathrm{m}^{2}$ ) and fixed color/intensity exclusion criterion within Metamorph. Labeling within each of the four sections was averaged for a final estimate of labeling within each cochlear turn (see Fig. 4). To verify that use of a fixed criterion did not bias the final result, we also evaluated immunolabeled area using a variable threshold criterion that included only discrete, darkly stained puncta, and a criterion in which threshold was adjusted until all immunolabeled area was included. Immunolabeled area varied with the applied criterion (i.e., labeled area was greatest when all immunolabeled area was included), but there were no systematic differences in the pattern of results. Because there was nonspecific labeling of the remaining gluteraldehyde-fixed tissues, lesion success was verified using brain stem analyses in animals with tissues that were fixed with gluteraldehyde.

\section{RESULTS}

\section{Anatomy}

Brain stem quantification. The area of LSO that was undamaged (i.e., intact cell bodies were evident) on 


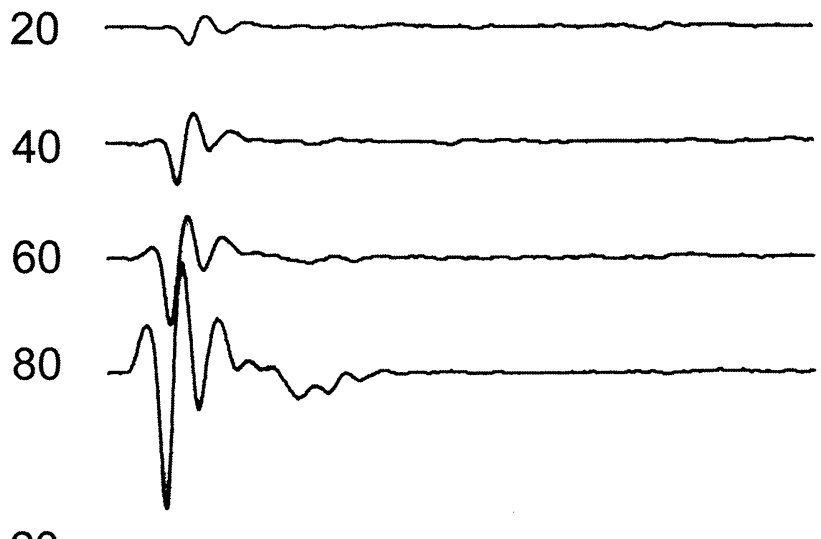

20

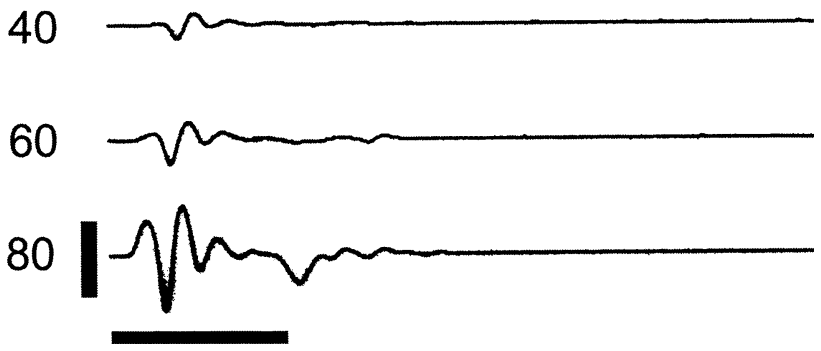

FIG. 5. The sound-evoked whole-nerve compound action potential (CAP) response of the auditory nerve is shown for a subset of the levels tested (20,40, 60, 80- dB SPL). Waveforms are in response to a $14-\mathrm{kHz}$ acoustic signal (5 ms, see horizontal scale bar) and are from a control animal (top) and an animal in which the lateral superior olive (LSO) was lesioned (bottom). Data from the LSO-lesioned animal were obtained on the seventh day postlesion. Vertical scale bar $=170 \mu \mathrm{V}$.

LSO that was not damaged by the melittin injection in this animal, although we note that a precise tonotopic map of the guinea pig LSO is not available. The reduction in synaptic labeling evident across the other cochlear turns was not accompanied by gross changes in the inner spiral bundle or the tunnel crossing fibers. Labeling in the vicinity of outer hair cells was unaffected, suggesting there was no disruption of the medial efferent neurons.

\section{Electrophysiology}

Threshold. Examples of typical CAP waveforms are depicted in Figure 5. All scoring of CAP waveforms was conducted by observers blind to experimental condition. Threshold was defined as the lowest level at which a CAP response could be identified by visual inspection. CAP amplitude was typically $3-5 \mu \mathrm{V}$ at threshold. There were several animals for which CAP amplitude, at 0 -dB SPL, was greater than the 3-5 $\mu \mathrm{V}$ criterion. Under these conditions, threshold was arbitrarily scored as 0-dB SPL for summary purposes because 0-dB SPL was the lowest level tested. CAP
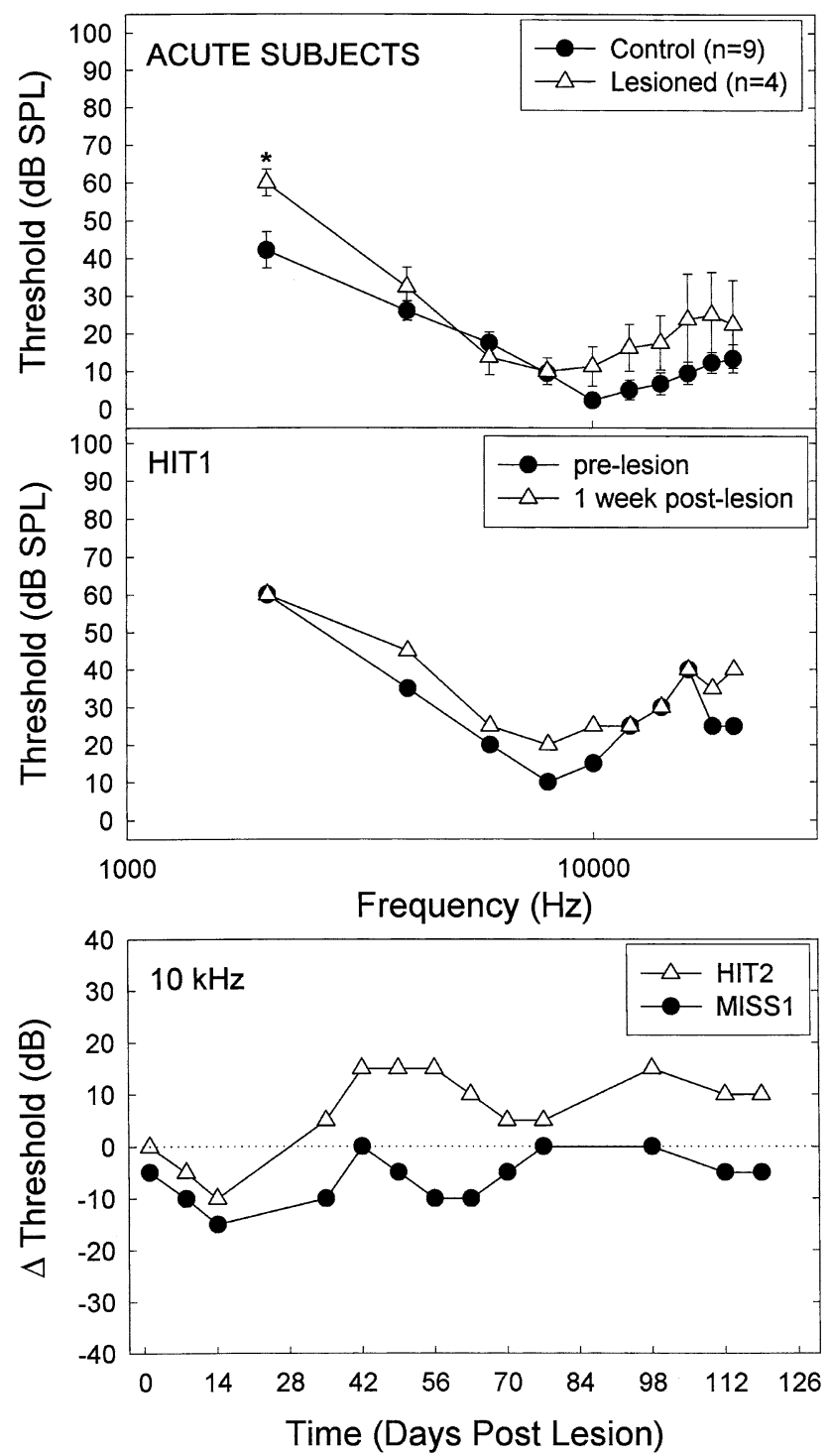

FIG. 6. Threshold, defined as the lowest signal level (dB SPL) that elicited a compound action potential (CAP) response, was determined for all animals. Top: Mean threshold $( \pm$ SE) for acute electrophysiology animals. All lesioned animal thresholds were determined 1 week postlesion. Asterisks denote statistically reliable differences between lesioned and unlesioned control animals $\left(p^{\prime} s<\right.$ 0.05). Middle: Thresholds for chronic animal HIT1 were determined before and 1 week after lesioning the lateral superior olive (LSO). Bottom: Thresholds for chronic animals HIT2 and MISS1 were determined at $10 \mathrm{kHz}$ before and after the lesion surgery. Lesion-induced change from prelesion threshold is depicted. Brain stem sections from animal HIT2 exhibited targeted disruption of LSO; brain stem sections from animal MISS1 showed no cytotoxin-induced trauma. Postlesion assessment was conducted at time points extending to 17 weeks.

thresholds were within the range of variation for pigmented guinea pig CAP thresholds as reported across different laboratories (e.g., Dum 1983; Thorne and Gavin 1985; Fechter et al. 1992; Charlet de Sauvage et al. 1996; Mulheran and Harpur 1998). 

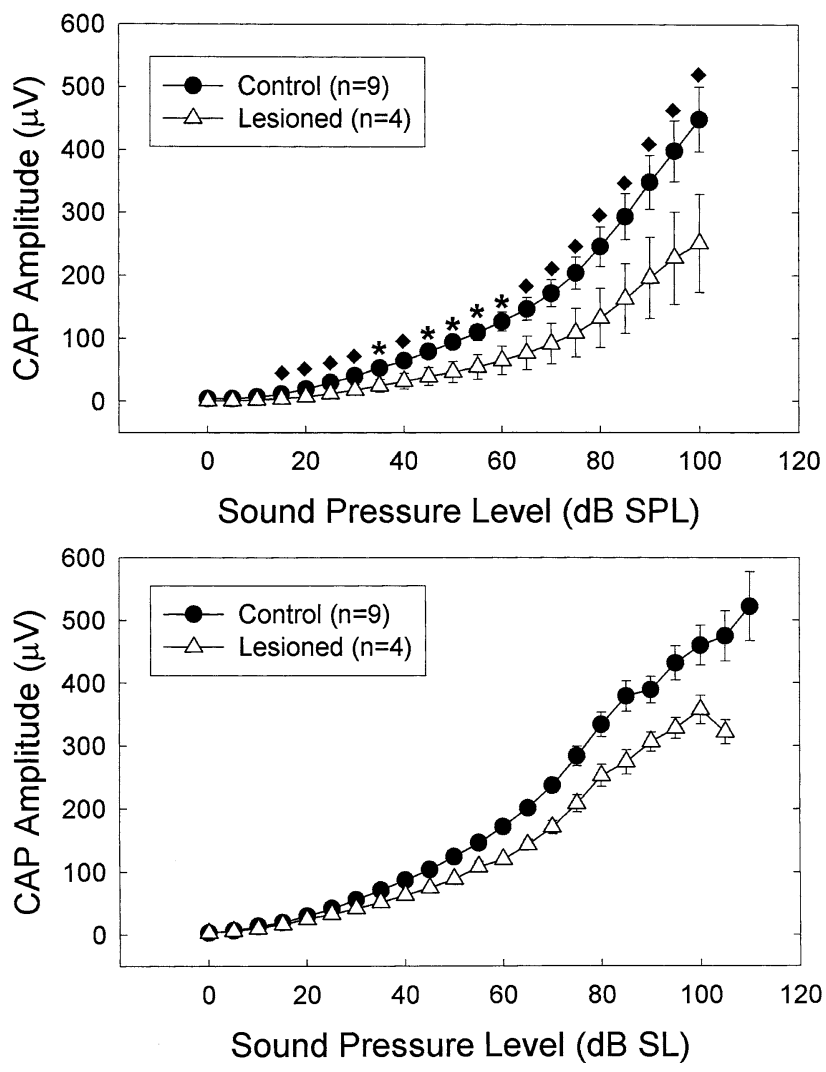

FIG. 7. CAP amplitude, defined as the amplitude of the N1-P1 response component, was determined for all frequency/level combinations for acute electrophysiology test animals. The $20-\mathrm{kHz} 100-$ dB SPL data were discarded due to acoustic signal distortion at this frequency/level combination. Mean CAP amplitude ( \pm SE), averaged within levels and across frequencies, is depicted. All lesioned animals were assessed 1 week postlesion. Top: CAP amplitude for sound intensity levels measured in $\mathrm{dB}$ SPL. Asterisks denote statistically reliable pairwise differences between lesioned and unlesioned control animals $\left(p^{\prime} s<0.05\right)$. Diamonds denote differences that approached statistical reliability $\left(p^{\prime} s<0.10\right)$. Bottom: CAP amplitude for sound intensity levels normalized to account for differences in threshold sensitivity. Intensity is expressed as $\mathrm{dB}$ sensation level $(\mathrm{dB}$ $\mathrm{SL}$, or, equivalently, $\mathrm{dB}$ above threshold). Because the overall statistical reliability of the lesion-induced change in CAP amplitude was greater than 0.10 , pairwise comparisons were not conducted.

Threshold data from lesioned and control animals (mean $+/-$ standard error) tested in the acute procedure are summarized in Figure 6 (top). For each test frequency, univariate ANOVAs were conducted using SPSS version 10.1 (SPSS Inc., Chicago, IL). Thresholds were significantly elevated in lesioned animals at $2 \mathrm{kHz}(F=5.332, d \mathrm{f}=1,11 ; p<0.05)$. The corresponding data from the chronic animals are depicted in the lower panels of Figure 6 (middle: HIT1; bottom: HIT2, MISS1). Both acute (top) and chronic (middle, bottom) lesion groups showed a tendency for threshold elevation at various frequencies. Thresholds improved in only one case, that in which the lesion did not damage LSO (MISS1).
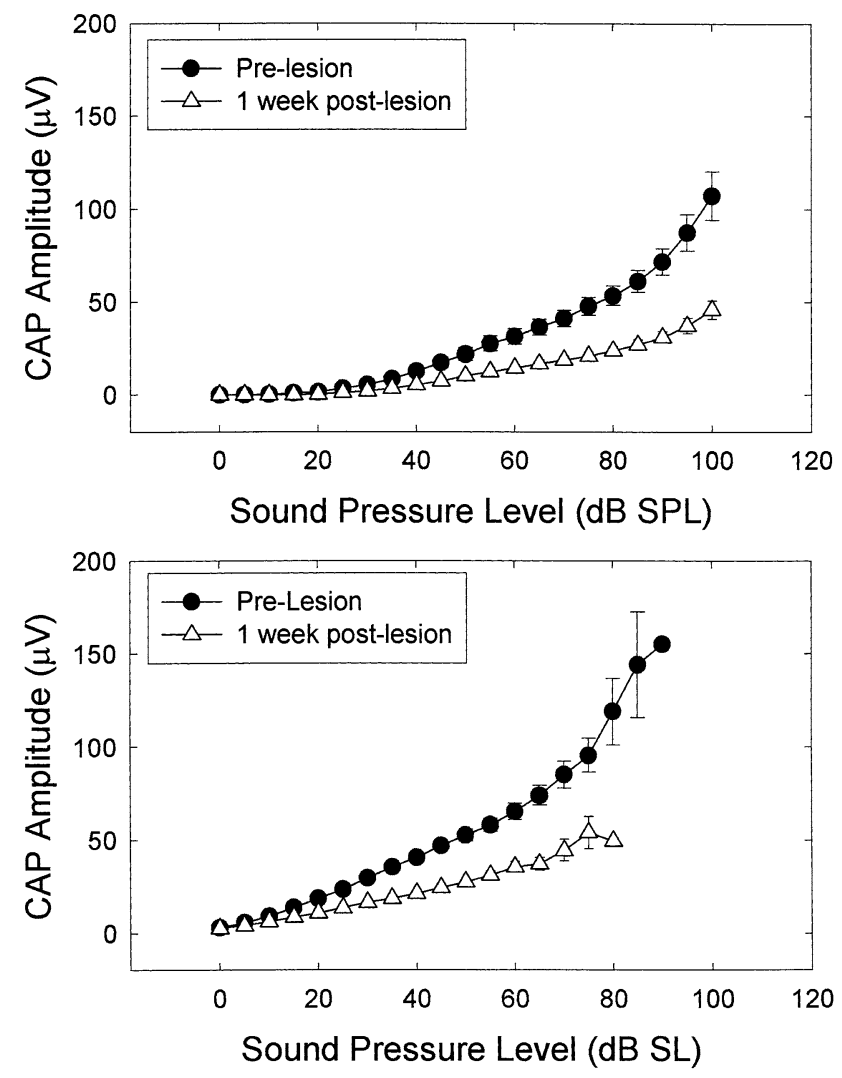

FIG. 8. CAP amplitude, defined as the amplitude of the N1-P1 response component, was determined for all frequency/level combinations for animal HIT1 prior to and 1 week after melittin was injected into the lateral superior olive (LSO). The $20-\mathrm{kHz} 100-\mathrm{dB}$ SPL data were discarded due to acoustic signal distortion at this frequency/level combination. CAP amplitude, averaged within levels and across frequencies, is depicted. Top: CAP amplitude for sound intensity levels measured in dB SPL. Bottom: CAP amplitude for sound intensity levels normalized to account for differences in threshold sensitivity. Intensity is expressed as dB sensation level ( $d B$ $\mathrm{SL}$, or, equivalently, $\mathrm{dB}$ above threshold).

N1 latency. N1 latency was compared across frequency and intensity for lesion and control groups using a three-way repeated-measures ANOVA in which group was treated as a between-subject variable and frequency and intensity were treated as withinsubject variables. There were no significant effects of group, and no significant interactions for group $\times$ frequency or group $\times$ intensity. Statistical analyses were first conducted on the latency data using the raw data. These analyses were repeated using a fitted data set in which missing (i.e., subthreshold) latency values were extrapolated from the existing data set. The fitted data were derived using a 3-parameter model where fit $(x)=a_{0} * \ln \left(x+a_{1}\right)+a_{2}$. The use of this 3parameter model allowed for an excellent fit of the data across the wide range of intensity and frequency used in this study. No significant differences were detected between raw and fitted data. However, the fitted data set had the advantage of being a complete 
data set that was amenable to standard statistical analyses for repeated measures with greater power than was available with the raw data set that necessitated a multiple pairwise comparisons approach. Taken together, these data suggest the integrity of the LSO had very little effect on N1 latency. Data from our chronic animals were consistent with this observation. There was no evidence of lesion-induced differences in latency of the CAP assessed prelesion and postlesion.

CAP amplitude. The main effect of the LSO lesion was a depression in CAP amplitude. This effect was evident when responses were compared for equivalent sound levels (dB SPL) as well as equivalent sensation levels ( $\mathrm{dB}$ SL). Moreover, lesion-induced decreases in CAP amplitude were evident in both acute (Fig. 7) and chronic (Fig. 8) test animals.

A three-way repeated-measures ANOVA was used to compare control and lesioned animals across all test frequency and level combinations. A main effect of frequency was revealed, indicating that CAP amplitude was greater at the higher frequencies than at the lower frequencies $(F=14.891, d f=9,99 ; p<$ $0.001)$. This result was not surprising as CAP was assessed at the round window. In addition, a group $\times$ intensity effect was revealed $(F=3.744, d \mathrm{f}=20,220 ; p$ $<0.001)$, indicating that CAP amplitude in lesioned animals was always smaller than CAP amplitude in control animals but differences varied with intensity. There were no significant interactions of group $x$ frequency or group $x$ frequency $x$ intensity. This indicated that the CAP amplitude depression in lesioned animals was consistent across frequency. We therefore depict CAP amplitude averaged across frequency for each intensity level.

The statistical reliability of lesion-induced changes was analyzed first at equivalent sound pressure levels (dB SPL) and then after sound levels were normalized to threshold (dB SL). The amplitude of the CAP sound-evoked response was smaller in lesioned animals than in control animals when expressed as $\mathrm{dB}$ SPL $(F=4.547, d \mathrm{f}=1,11 ; p=0.056)$. The statistical reliability of the lesion-induced effect was reduced $(F=1.789, d \mathrm{f}=1,11 ; p=0.208)$ after normalizing for sensation level. Therefore, pairwise comparisons were conducted only for data expressed in dB SPL units. There were no reliable group differences at $0-10 \mathrm{~dB}$ SPL ( $p$ 's $>0.10)$; other within-level group comparisons revealed the depression in CAP amplitude in lesioned animals was statistically reliable at 35-dB SPL and 45-60-dB SPL $(p$ 's $<0.05)$. The differences approached statistical reliability at all other levels including 15-dB SPL and above ( $p$ 's $<0.10)$.

Lesioning the LSO similarly depressed CAP amplitude for animal HIT1, who was tested prelesion and 1-week postlesion (Fig. 8, top: dB SPL; bottom:
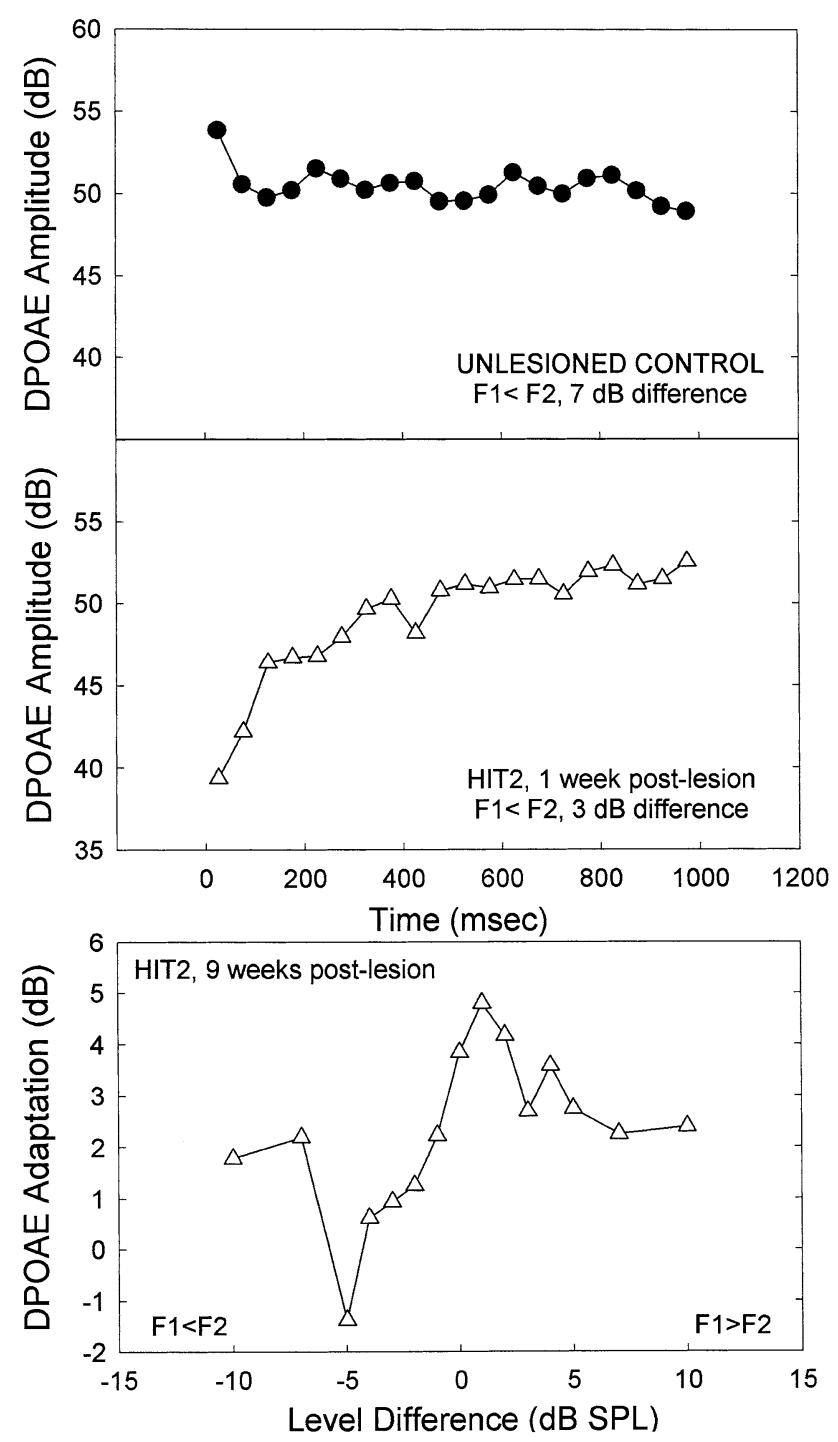

FIG. 9. Distortion product otoacoustic emissions (DPOAEs) show a rapid adaptation shortly after signal onset when the medial efferent pathway is intact. DPOAE adaptation is depicted for an unlesioned control animal (top, CGL073) and HIT2 (middle); HIT2 underwent a targeted disruption of the lateral superior olive (LSO). Variation in amplitude of the adaptation component is consistent with unlesioned animals tested in this laboratory as well as other laboratories. The ratio of levels of Fl and F2 were systematically varied across a wide range for both animals. The amplitude of the adaptation across level combinations is depicted in the bottom panel for animal HIT2.

dB SL). Animals HIT2 and MISS1 were repeatedly tested at a single frequency $(10 \mathrm{kHz})$ over a longer time interval. HIT2 was unlike other LSO-lesioned animals in that CAP amplitude was unchanged, relative to prelesion baseline, at 1-2 weeks postlesion. Testing was not conducted at weeks 3 and 4; however, by week 5 , a very stable long-term (up to 17 week) depression was evident in both raw (dB SPL) and normalized (dB SL) responses. In contrast, CAP amplitude was not depressed in MISS1, the animal in which LSO was intact after the melittin injection. 
DPOAE adaptation. Adaptation of the DPOAE response was assessed in all of the animals that received chronic round window implants and lesions. Adaptation of the DPOAE response was evident in control (Fig. 9, top) and LSO-lesioned animals (Fig. 9, middle). The amplitude of the adaptation was variable across animals, which is consistent with observations from other animals tested in this laboratory as well as the variability described by Maison and Liberman (2000). They classified animals with 10-25 dB of adaptation as "strong MOC reflex" and animals with less than $2 \mathrm{~dB}$ of adaptation as "weak MOC reflex."

DPOAE amplitude was carefully examined at multiple level combinations for animal HIT2. As the ratio of F1 and F2 levels was shifted, we observed a change in the direction of adaptation as well as the amplitude of adaptation (see Fig. 9, bottom). These effects critically depend on the integrity of the crossed medial olivocochlear neurons (Liberman et al. 1996; Kujawa and Liberman 2001). Taken together, these results suggest that the medial efferent innervation of the cochlea was relatively intact functionally, at least in the animals for which DPOAE amplitude was assessed.

\section{DISCUSSION}

The present results suggest that lateral efferent innervation of the cochlea modulates auditory nerve afferent output. After lesioning the LSO, CAP amplitude was clearly depressed. The effect was evident when we compared lesioned and unlesioned animals using an acute CAP assessment paradigm. The effect was similarly striking when we compared prelesion and postlesion data collected from the animals tested in a chronic paradigm. Neither differences in N1 latency nor overall changes in threshold sensitivity accompanied the compression of CAP amplitude. Because there was a trend toward higher thresholds in lesioned animals at some frequencies, however, we adjusted the CAP amplitude data to account for any differences in threshold sensitivity. After converting to sensation level, the results were identical in that CAP amplitude was depressed in lesioned animals relative to control animals.

Disrupting the lateral efferent pathway could depress CAP if a relatively smaller population of auditory nerve fibers were activated in the auditory system that lacks (or has a reduced) lateral efferent innervation. Alternatively, a lesion-induced breakdown in the synchronization of single-unit firing could result in smaller overall CAP amplitude. The present data do not allow a distinction between these possibilities. However, the lack of effect of the lesion on N1 latency suggests that if there were a lesion-induced disruption in synchronous firing, the effect was limited to a small number of neurons. Gross disruption of synchronous firing eliminates N1 (Goldstein and Kiang 1958). We note that the possibility of the LSO lesion affecting adapted neural firing rates (as shown by Zheng et al. 1999, after OCB transection) is not addressed by the current data. Neural response adaptation (either across the duration of the stimulus or across presentations of multiple stimuli) does not occur for brief acoustic stimuli separated by long inter-stimulus intervals (such as those used in the current investigation; see Peake et al. 1962; Kiang et al. 1965).

Although we did not specifically include control animals in which the skull was opened but melittin was not injected, we did examine electrophysiological data from two animals in which the lesion missed the LSO. One of these animals was tested under the acute test paradigm. Data from this animal (which are not depicted) were indistinguishable from the control animals that had not undergone the lesion surgery. The second animal (MISS1) was tested in the chronic test paradigm. Animal MISS1 was unlike the lesioned animals in that(1) thresholds showed no increase from prelesion baselines and (2) CAP amplitude showed no postlesion depression. Thus, it is unlikely that the differences reported here can be attributed to uncontrolled consequences of the surgical procedure. That is, the placement of the lesion within LSO was critical in evoking the observed depression of CAP amplitude.

The LSO is tonotopically organized such that lower frequencies are represented more laterally. Tonotopic distribution across LSO has been mapped in gerbils (Sanes et al. 1989), rats (Sommer et al. 1993; Kelly et al. 1998), and cats (Tsuchitani and Boudreau 1966; Guinan et al. 1972; Tsuchitani 1977). Injections of dye into the base or apex of the guinea pig cochlea produce labeling in LSO suggestive of a similarly organized tonotopic map (see Stopp 1983; Aschoff and Ostwald 1987; Robertson et al. 1987). Based on the general tonotopic organization of LSO, lower frequencies might be relatively more affected than higher frequencies in the current experimental animals because lesions predominantly affected the lateral limb of the LSO. Such an effect was generally evident in the current investigation [see Tables 1 (80$\mathrm{dB}$ SPL) and 2 (60-dB SPL)]. However, the lack of statistically reliable interactions of group $\times$ frequency or group $\times$ frequency $\times$ intensity indicate differences across frequency were not statistically reliable. Taken together, the lack of statistically different effects across frequencies probably reflects the fact that the medial limb was at least partially damaged in all lesioned subjects. Moreover, the medial limb was completely lesioned for most subjects in a subset of brain stem sections. 
TABLE 1

Percent change in CAP amplitude at 80-dB SPL

\begin{tabular}{lcccccccccc}
\hline & \multicolumn{10}{c}{ Frequency $(\mathrm{kHz})$} \\
\cline { 2 - 11 } & 2 & 4 & 6 & 8 & 10 & 12 & 14 & 16 & 18 & 20 \\
\hline Acute $^{\mathrm{a}}$ & -74 & -53 & -39 & -46 & -39 & -45 & -47 & -48 & -50 & -39 \\
HIT1 $^{\mathrm{b}}$ & -54 & -54 & -58 & -56 & -56 & -43 & -55 & -48 & -58 & -66 \\
HIT2 $^{\mathrm{c}}$ & & & & & -75 & & & & & \\
MISSI $^{\mathrm{c}, \mathrm{d}}$ & & & & & -3 & & & & & \\
\hline
\end{tabular}

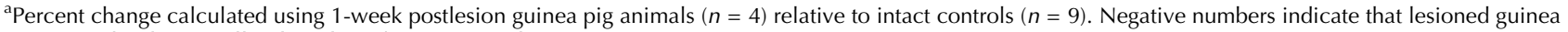
pig CAP amplitude is smaller than that of intact controls.

${ }^{\mathrm{b}}$ Percent change calculated using 1-week postlesion HIT1 animal data relative to prelesion within-subject control data. Negative numbers indicate CAP amplitude was smaller at 1 week postlesion.

${ }^{c}$ Percent change calculated using 17-week postlesion HIT2 animal data relative to prelesion within-subject control data. Negative numbers indicate CAP amplitude was smaller at the final 17-week postlesion time point.

${ }^{\mathrm{d}} \mathrm{LSO}$ intact.

TABLE 2

\begin{tabular}{|c|c|c|c|c|c|c|c|c|c|c|}
\hline \multicolumn{11}{|c|}{ Percent change in CAP amplitude at $60-\mathrm{dB}$ SPL } \\
\hline & \multicolumn{10}{|c|}{ Frequency $(k H z)$} \\
\hline & 2 & 4 & 6 & 8 & 10 & 12 & 14 & 16 & 18 & 20 \\
\hline $\begin{array}{l}\text { Acute }^{\mathrm{a}} \\
\text { HIT1 }^{\mathrm{b}} \\
\mathrm{HIT}^{\mathrm{c}} \\
\text { MISSI }^{\mathrm{c}, \mathrm{d}}\end{array}$ & $\begin{array}{l}-87 \\
-36\end{array}$ & $\begin{array}{l}-56 \\
-56\end{array}$ & $\begin{array}{l}-37 \\
-58\end{array}$ & $\begin{array}{l}-42 \\
-53\end{array}$ & $\begin{array}{l}-41 \\
-54 \\
-83 \\
+54\end{array}$ & $\begin{array}{l}-44 \\
-46\end{array}$ & $\begin{array}{l}-54 \\
-47\end{array}$ & $\begin{array}{l}-57 \\
-50\end{array}$ & $\begin{array}{l}-53 \\
-64\end{array}$ & $\begin{array}{l}-45 \\
-64\end{array}$ \\
\hline
\end{tabular}

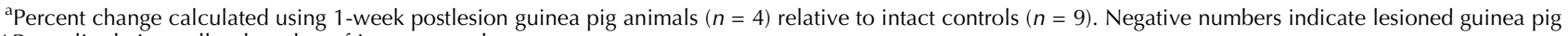
CAP amplitude is smaller than that of intact controls.

${ }^{\mathrm{b}}$ Percent change calculated using 1-week postlesion HIT1 animal data relative to prelesion within-subject control data. Negative numbers indicate CAP amplitude was smaller at 1 week postlesion.

'Percent change calculated using 17-week postlesion HIT2 animal data relative to prelesion within-subject control data. Negative numbers indicate CAP amplitude was smaller at the final 17-week postlesion time point.

${ }^{\mathrm{d}} \mathrm{LSO}$ intact.

Because frequency-specific effects presumably vary based on the specific pattern of damage to the LSO in each individual animal, we explored frequency effects for HIT1, the only chronic animal tested at multiple frequencies. The melittin injection into the brain stem of this animal disrupted virtually all of the LSO (see Fig. 10, top). Intact cell bodies were observed only in the ventromedial region of the LSO. Postlesion CAP amplitude for HIT1 was most depressed at our lower test frequencies (i.e., $4-10 \mathrm{kHz}$ ), somewhat less affected within the $12-16 \mathrm{kHz}$ frequency range (presumably corresponding to the intact cell bodies within ventromedial LSO), and more depressed at the highest test frequencies (i.e., 18-20 $\mathrm{kHz}$ ). This effect is evident at the arbitrarily selected levels presented in Tables 1 and 2, as well as across levels as shown in subset of frequencies depicted in Figure 10.

That the brain stem lesion targeted to LSO in fact disrupted the lateral efferent innervation of the cochlea is demonstrated by the reduction in synaptophysin immunolabeling in the animals showing sy- napse-specific labeling. With the exception of the segment taken from the second turn of the cochlea in one animal, synaptophysin-immunolabeling was reduced in the ear ipsilateral to the LSO lesion (compared with the control ear contralateral to the lesion). Thus, the LSO lesions decreased the innervation of the auditory nerve dendrites by lateral efferent neurons. Of particular importance, we note that the lesion in the brain stem of CGL067 was centered in the lateral limb (i.e., the lower frequency limb) of the LSO and only a small portion of ventromedial LSO was intact after the injection of melittin. In the cochlea, synaptophysin immunolabeling was most reduced in the upper turns, corresponding to the lower-frequency regions (see Fig. 3, panels BD; Fig. 4). That labeling was intact in the second turn of the cochlea may reflect innervation from ventromedial LSO, which was intact in some brain stem sections. A frequency-specific correlation could not be ascertained for GP2-1 (Fig. 3, panel A), as the upper turns of the cochlea were damaged during dissection of the tissue. 

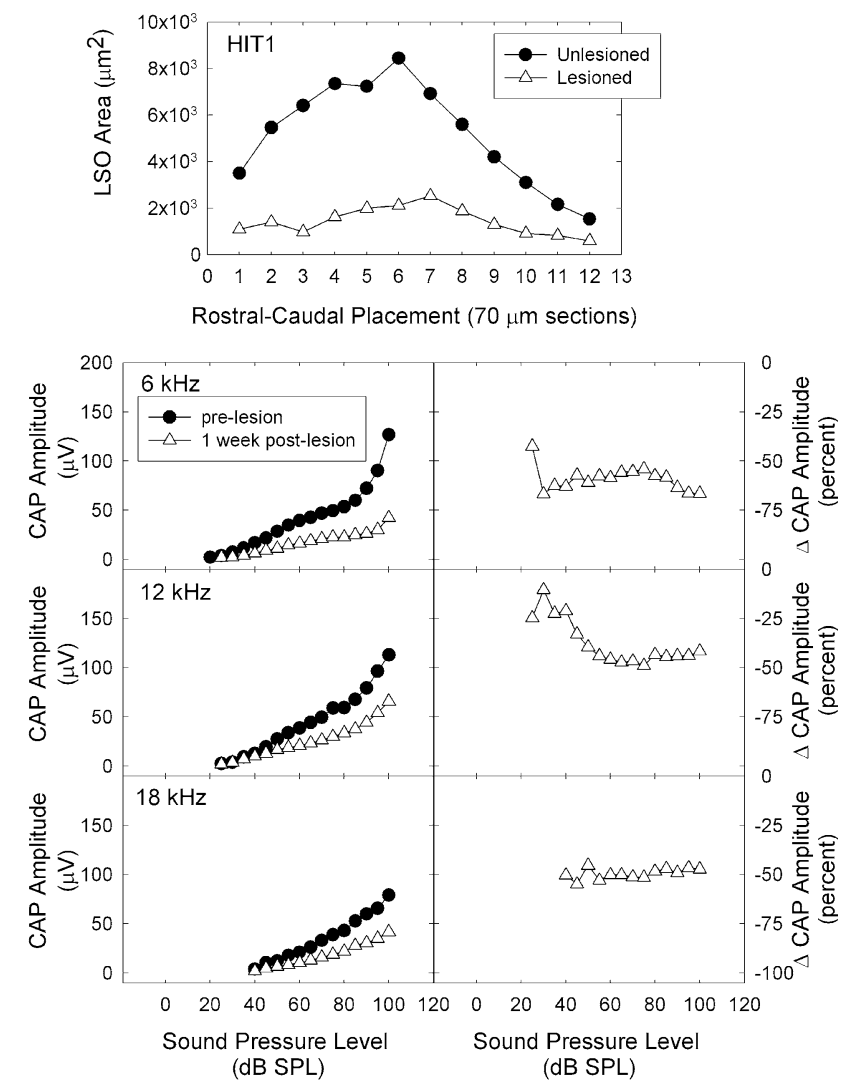

FIG. 10. Top. Area of intact (undamaged) lateral superior olive (LSO) was measured following injection of melittin into the vicinity of LSO (e.g., "Lesioned") in the animal identified as HIT1. Control comparisons were provided from measurements of LSO area in contralateral, uninjected LSO (e.g., "Unlesioned"). Section 1 was the most caudal section in which LSO appeared. Sections were sequentially numbered until LSO was no longer evident. Bottom, left. Amplitude of the compound action potential (CAP) response of the auditory nerve is depicted across stimulus levels $(\mathrm{dB} S \mathrm{SL})$ at three frequencies $(6,12$, and $18 \mathrm{kHz})$. CAP was assessed prelesion using a chronically implanted electrode, as well as 1 week postlesion. Right. Percent change in CAP amplitude induced by the LSO lesion, at frequencies corresponding to those depicted in the left panels. Negative numbers represent a depression in CAP amplitude. Percent change in CAP amplitude at other test frequencies is summarized for a subset of stimulus intensities in Tables 1 and 2 .

It is unlikely that disruption of the medial efferent pathways resulted in the observed effects. First, functional integrity of the medial efferent neurons was verified empirically in the chronic test animals. Specifically, DPOAE amplitude adaptation was measured as in the studies of Liberman and colleagues (e.g., Liberman et al. 1996; Maison and Liberman 2000; Kujawa and Liberman 2001). While DPOAE adaption revealed at least some functionally intact medial efferent innervation of the cochlea, we note that the data do not allow evaluation of subtle lesioninduced changes in medial efferent function because DPOAE adaptation was not assessed prelesion. Second, integrity of the medial efferent neurons was evaluated anatomically. For those brain stem sections stained with cresyl violet, the integrity of the regions of the brain stem medial to LSO, i.e., areas in which medial efferent neurons originate, were assessed. This stain does not permit an assessment of the integrity of the OCB, composed of both medial and lateral efferent neurons traveling to the cochlea, however. Thus, brain stem sections from two animals were labeled using ACh-based histochemical reactions to allow visualization of the OCB. There was no evidence of damage to the OCB in these animals (HIT2, MISS1). Finally, there was no qualitative reduction in synaptophysin labeling under the outer hair cells in the cochlear tissues that were fixed with $4 \%$ paraformaldehyde. Thus, medial efferent projections to the cochlea did not appear to be disrupted in any of the functional or morphological analyses. Taken together, the evidence suggests the observed lesion-induced depression in the soundevoked CAP was not a consequence of consistent disruption to the medial efferent innervation of the cochlea.

Our findings support and extend previous suggestions that the lateral efferent innervation of the cochlea modulates auditory nerve activity. Liberman (1990) sectioned the OCB in cats and observed that single auditory nerve fibers showed a significant decrease in spontaneous activity. Although both medial and lateral efferent pathways are disrupted by sectioning the OCB, one explanation of the observed changes in auditory nerve activity was that the intact LOC system has a "net excitatory" effect (see Liberman 1990). De-efferentation-induced decreases in spontaneous activity have since been observed in chinchillas as well (Zheng et al. 1999). Finally, Groff and Liberman (2002) recently presented preliminary evidence that delivery of shock trains to the LSO enhances the sound-evoked CAP response of the auditory nerve. This enhancement of CAP amplitude was observed only in the cochlea ipsilateral to the stimulation site within the brain stem.

Both Liberman (1990) and Zheng et al. (1999) have proposed a model in which lateral efferent innervation of the cochlea produces a tonic, low-level discharge of auditory nerve fibers (i.e., spontaneous activity) which is reduced after de-efferentation. This excitatory effect could be mediated through a chronic release of neuroactive substances that directly excite the afferent fibers. There are at least two transmitter substances that, if eliminated from the afferent synapse, could produce the spontaneous rate depression described by Liberman (1990) and Zheng et al. (1999), as well as the depression of the wholenerve response described in the current report. Specifically, disrupting a tonic release of either ACh or dynorphin (dyn) from the lateral efferent neurons 
could depress auditory nerve activity. Although neither tonic nor sound-induced release of ACh or dyn from lateral efferent synapses has been empirically verified, there are functional and anatomical data supporting their ability to modulate the output of the auditory nerve.

When applied in the vicinity of the auditory nerve dendrites using microiontophoresis, ACh $(0.5 \mathrm{M})$ increases subsynaptic spiking and enhances glutamate-induced auditory nerve activity (Felix and Ehrenberger 1992). The prediction that CAP would be depressed in the absence of lateral efferent release of ACh is consistent with these results. This should be interpreted with caution, however, as Bobbin and Konishi (1971) reported that intracochlear perfusion of ACh $(250 \mu \mathrm{M})$ has no effect on CAP. Moreover, the combination of ACh $(250 \mu \mathrm{M})$ and eserine $(10 \mu \mathrm{M})$, a substance that blocks the metabolism of ACh, depressed the amplitude of CAP. Murugasu and Russell (1996) reported an elevation in CAP threshold when ACh $(100 \mu \mathrm{M})$ and physostigmine $(20 \mu \mathrm{M})$, a substance that prevents the breakdown of ACh, were perfused in the cochlea. Although Murugasu and Russell (1996) did not report the effects of the ACh perfusion on CAP amplitude, the threshold elevations they describe would likely be accompanied by a level-dependent depression in CAP amplitude. It is possible that the differences between the results of Felix and Ehrenberger (1992) and those of Bobbin and Konishi (1971) and Murugasu and Russell (1996) are related to the different perfusion procedures. Whereas Felix and Ehrenberger (1992) restricted ACh delivery to the vicinity of the auditory nerve dendrites, those investigators reporting inhibitory effects of ACh (e.g., Bobbin and Konishi 1971; Murugasu and Russell 1996) perfused the entire cochlea with ACh. Perfusion of the entire cochlea would result in stimulation of ACh receptors on the OHCs as well as those on the auditory nerve dendrites.

A second putative lateral efferent neurotransmitter that appears to have excitatory effects on afferent activity is dynorphin. Chinchillas treated intravenously with a dynorphin-like substance, (-)pentazocine, showed an enhancement of CAP amplitude and improvement in threshold sensitivity (Sahley et al. 1991; Sahley and Nodar 1994). These excitatory effects were antagonized by intravenous naloxone (Sahley et al. 1996b) and norbinaltorphimine applied to the round window membrane of the cochlea (Sahley et al. 1996a). The effects of dyn agonists on whole-nerve potentials have not yet been evaluated when dyn receptor agonists are infused directly into the cochlea. In addition, the effects of dyn agonists on single-unit auditory nerve activity remain to be determined.
Perhaps the best-characterized putative lateral efferent neurotransmitter is dopamine (DA). DA is postulated to mediate protection of the auditory nerve dendrites against trauma-induced swelling (Pujol et al. 1993; d'Aldin et al. 1995a, b), and also to preserve threshold sensitivity after trauma (d'Aldin et al. 1995a). This suggests that DA might "turn down" driven activity in the normal auditory system. During infusion of DA agonists, auditory nerve single-unit driven rates (Oestreicher et al. 1997; Ruel et al. 2001), the whole-nerve response (d'Aldin et al. 1995a, b; Ruel et al. 2001), and spontaneous firing rates [according to Ruel et al. (2001) but not Oestreicher et al. (1997)] are in fact decreased. Taken together, DA consistently depresses auditory nerve responses.

DA appears to reduce auditory nerve activity, but each of the past de-efferentation investigations (e.g., Liberman 1990; Zheng et al. 1999), as well as the current LSO lesion experiment, supports a net excitatory effect of lateral efferent innervation of the cochlea. That is, auditory nerve activity has been depressed in the absence of lateral efferent innervation. Thus, it initially seems that DA is not a primary determinant of auditory nerve activity. Although more speculative, we acknowledge there is at least one mechanism through which disruption of DA release by the lateral efferent neurons in the cochlea could result in a depression of CAP amplitude, as shown in the current findings. When DA receptors in the cochlea are blocked with the D1 receptor antagonist eticlopride or the D2 receptor antagonist SCH-23390, high-spontaneous-rate auditory nerve fibers show a transient increase in spontaneous rate followed by a depression in rate (Ruel et al. 2001). At least the eticlopride-induced depression in rate is accompanied by auditory nerve dendritic swelling (Ruel et al. 2001). If lack of D2 receptor activation underlies dendritic swelling and a related suppression of neural activity, then a lesion that reduces or eliminates the endogenous supply of DA might similarly result in dendritic swelling and depressed auditory nerve activity. Swelling following de-efferentation has been reported in monkeys (Bodian and Gucer 1980) and rats (Spangler and Warr 1987) but not cats (Liberman 1990).

In summary, our data show that the gross soundevoked auditory nerve potential, the CAP, is depressed following disruption of the lateral efferent pathway. These data support the suggestion that depressed single-unit auditory nerve activity after transection of the medial and lateral auditory efferent pathways is a consequence of lateral efferent de-innervation (e.g., Liberman 1990; Zheng et al. 1999). In the current investigation, the medial efferent innervation of the cochlea appeared to be functionally intact, at least in the animals in which we assessed 
DPOAE amplitude, and there was no morphological evidence of disruption to medial efferent neurons. Given the recent demonstration that electrical stimulation of cell bodies originating in the LSO enhances sound-evoked auditory nerve response (Groff and Liberman 2002), the data provide compelling evidence that lateral efferent neurons modulate auditory nerve activity that occurs spontaneously and as a result of acoustic stimulation.

\section{ACKNOWLEDGMENTS}

Support was provided by NIH-NIDCD P01-DC-00078 (SCB) and F32-DC-00367 (CGL). Acetylcholinesterase immunolabeling was conducted at Eaton-Peabody Laboratory; cochlear tissue preparation was done in R. Altschuler's laboratory; D. Dolan, H. Drewior, C. Ellinger, R. Griffith, K. Halsey, E. Macpherson, J. McLaren, D. Payer, and L. Pierchala provided technical assistance. We thank D. Dolan, M. C. Liberman, and J. Middlebrooks for comments on an earlier version of the paper.

\section{REFERENCES}

Albuquerque EX, Pereira EF, Braga MF, Matsubayashi H, AlkonDON M. Neuronal nicotinic receptors modulate synaptic function in the hippocampus and are sensitive to blockade by the convulsant strychnine and by the anti-Parkinson drug amantadine. Toxicol. Lett. 102-103:211-218, 1998.

Aschoff A, Ostwald J. Different origins of cochlear efferents in some bat species, rats, and guinea pigs. J. Comp. Neurol. 264:56-72, 1987.

BECHINGER B. Structure and functions of channel-forming peptides: magainins, cecropins, melittin and alamethicin. J. Membr. Biol. 156:197-211, 1997.

Bledsoe Jr SC, Snead CR, Helfert RH, Prasad V, Wenthold RJ, AltsChuler RA. Immunocytochemical and lesion studies support the hypothesis that the projection from the medial nucleus of the trapezoid body to the lateral superior olive is glycinergic. Brain Res. 517:189-194, 1990.

Bobisn RP, Konishi T. Acetylcholine mimics crossed olivocochlear bundle stimulation. Nat. New Biol. 231:222-223, 1971.

BobBin RP, KonISHI T. Action of cholinergic and anticholinergic drugs at the crossed olivocochlear bundle-hair cell junction. Acta Otolaryngol. (Stockh.) 77:56-65, 1974.

Bodian D, Gucer G. Denervation study of synapses of organ of Corti of old world monkeys. J. Comp. Neurol. 192:785-796, 1980.

Burgess BJ, AdAms JC, NAdOL JR JB. Morphologic evidence for innervation of Deiters' and Hensen's cells in the guinea pig. Hear. Res. 108:74-82, 1997.

Charlet de Sauvage R, da Costa DL, Erre JP, Aran JM. Changes in $\mathrm{CM}$ and CAP with sedation and temperature in the guinea pig: facts and interpretation. Hear. Res. 102:15-27, 1996.

D’Aldin C, Puel JL, Leduce R, Crambes O, Eybalin M, Pujol R. Effects of a dopaminergic agonist in the guinea pig cochlea. Hear. Res. 90:202-211, 1995a.

d’Aldin C, Eybalin M, Puel JL, Charachon G, Ladrech S, Renard N, Pujol R. Synaptic connections and putative functions of the dopaminergic innervation of the guinea pig cochlea. Eur. Arch. Otorhinolaryngol. 252:270-274, 1995b.
Desmedt JE, Monaco P. Mode of action of the efferent olivocochlear bundle on the inner ear. Nature 192:1263-1265, 1961.

Dolan DF, Yamasoba T, Leonova E, Beyer LA, Raphael Y. Morphological and physiological effects of long duration infusion of strychnine into the organ of Corti. J Neurocytol. 28:197-206, 1999.

Dum N. Age-dependent changes of the compound action potential in the guinea pig. Arch. Otorhinolaryngol. 238:179-187, 1983.

Elgoyhen AB, Johnson DS, Boulter J, Vetter DE, Heinemann S. Alpha9: an acetylcholine receptor with novel pharmacological properties expressed in rat cochlear hair cells. Cell 79:705-715, 1994.

Elgoyhen AB, Vetter DE, Katz E, Rothlin CV, Heinemann SF, BoULTER J. Alpha10: a determinant of nicotinic cholinergic receptor function in mammalian vestibular and cochlear mechanosensory hair cells. Proc. Natl. Acad. Sci. U.S.A. 98:3501-3506, 2001.

Eybalin M. Neurotransmitters and neuromodulators of the mammalian cochlea. Physiol. Rev. 73:309-373, 1993.

Fechter LD, Clerici WJ, Yao L, Hoeffding V. Rapid disruption of cochlear function and structure by trimethyltin in the guinea pig. Hear. Res. 58:166-174, 1992.

Felix D, Ehrenberger K. The efferent modulation of mammalian inner hair cell afferents. Hear. Res. 64:1-5, 1992.

FinLAYSON PG, CASPARY DM. Synaptic potentials of chinchilla lateral superior olivary neurons. Hear. Res. 38:221-228, 1989.

Gardi JN, Bledsoe JR SC. The use of kainic acid for studying the origins of scalp-recorded auditory brainstem responses in the guinea pig. Neurosci. Lett. 26:143-149, 1981.

GIFFORD ML, GUINAN JR JJ. Effects of electrical stimulation of medial olivocochlear neurons on ipsilateral and contralateral cochlear responses. Hear. Res. 29:179-194, 1987.

GoLDSTEIN MHJ, KIANG NYS. Synchrony of neural activity in electric responses evoked by transient acoustic stimuli. J. Acoust. Soc. Am. 30:107-114, 1958.

Gotti C, Moretti M, Maggi R, Longhi R, Hanke W, Kuinke N, Clementi F. Alpha7 and alpha8 nicotinic receptor subtypes immunopurified from chick retina have different immunological, pharmacological and functional properties. Eur. J. Neurosci. 9:1201-1211, 1997.

Groff JA, Liberman MC. Brainstem stimulation causes long-lasting enhancement of cochlear neural activity. Assoc. Res. Otolaryngol. Abstr. 25:239, 2002.

Guinan JR JJ, Norris BE, Guinan SS. Single auditory units in the superior olivary complex. II: Locations of unit categories and tonotopic organization. Int. J. Neurosci. 4:147-166, 1972.

Kelly JB, Liscum A, van Adel B, Ito M. Projections from the superior olive and lateral lemniscus to tonotopic regions of the rat's inferior colliculus. Hear. Res. 116:43-54, 1998.

Kiang NYS, Watanabe T, Thomas EC, Clark LF. Discharge Patterns of Single Fibers in the Cat's Auditory Nerve, Res. Monogr. 35. MIT Press, Cambridge, MA, 1965,

Kourie JI, Shorthouse AA. Properties of cytotoxic peptide-formed ion channels. Am. J. Physiol. Cell Physiol. 278:C1063-1087, 2000.

Kujawa SG, Liberman MC. Conditioning-related protection from acoustic injury: effects of chronic deefferentation and sham surgery. J. Neurophysiol. 78:3095-3106, 1997.

KuJAwA SG, Liberman MC. Effects of olivocochlear feedback on distortion product otoacoustic emissions in guinea pig. J. Assoc. Res. Otolaryngol. 2:268-278, 2001.

Le Prell CG, Bledsoe Jr SC, Bobbin RP, Puel JL. Neurotransmission in the inner ear: Functional and molecular analyses. In: Santos-Sacchi J, Jahn AF (eds) Physiology of the Ear, 2nd ed. Singular Publishing, New York, 2001, pp 575-611

LI L, KELLY JB. Binaural responses in rat inferior colliculus following kainic acid lesions of the superior olive: interaural intensity difference functions. Hear. Res. 61:73-85, 1992. 
LiBERMAN MC. Effects of chronic cochlear de-efferentation on auditory-nerve response. Hear. Res. 49:209-223, 1990.

Liberman MC. The olivocochlear efferent bundle and susceptibility of the inner ear to acoustic injury. J. Neurophysiol. 65:123-132, 1991.

Liberman MC, Puria S, Guinan Jr JJ. The ipsilaterally evoked olivocochlear reflex causes rapid adaptation of the 2f1- $\mathrm{f} 2$ distortion product otoacoustic emission. J. Acoust Soc. Am. 99:3572-3584, 1996.

Maison SF, Liberman MC. Predicting vulnerability to acoustic injury with a noninvasive assay of olivocochlear reflex strength. J. Neurosci. 20:4701-4707, 2000.

Matsubayashi H, Alkondon M, Pereira EF, Swanson KL, AlbuQUERQUE EX. Strychnine: a potent competitive antagonist of alpha-bungarotoxin-sensitive nicotinic acetylcholine receptors in rat hippocampal neurons. J. Pharmacol. Exp. Ther. 284:904913, 1998.

Morley BJ, Li HS, Hiel H, Drescher DG, Elgoyhen AB. Identification of the subunits of the nicotinic cholinergic receptors in the rat cochlea using RT-PCR and in situ hybridization. Brain Res. Mol. Brain Res. 53:78-87, 1998.

Mulheran M, Harpur ES. The effect of gentamicin and furosemide given in combination on cochlear potentials in the guinea pig. Br. J. Audiol. 32:47-56, 1998.

Murugasu E, Russell IJ. The role of calcium on the effects of intracochlear acetylcholine perfusion on basilar membrane displacement in the basal turn of the guinea pig cochlea. Aud. Neurosci. 2:363-376, 1996.

National Research Council. Guide for the Care and Use of Laboratory Animals. National Academy Press, Washington, DC, 1996,

Oestreicher E, Arnold W, Ehrenberger K, Felix D. Dopamine regulates the glutamatergic inner hair cell activity in guinea pigs. Hear. Res. 107:46-52, 1997.

OsEN KK, Rотн K. Histochemical localization of cholinesterases in the cochlear nuclei of the cat, with notes on the origin of acetylcholinesterase-positive afferents and the superior olive. Brain Res. 16:165-185, 1969.

Park HJ, Niedzielski AS, Wenthold RJ. Expression of the nicotinic acetylcholine receptor subunit, alpha9, in the guinea pig cochlea. Hear. Res. 112:95-105, 1997.

Peake WT, Goldstein MHJ, KIANg NYS. Responses of the auditory nerve to repetitive acoustic stimulation. J. Acoust. Soc. Am. 34:562-570, 1962.

Puel JL. Chemical synaptic transmission in the cochlea. Prog. Neurobiol. 47:449-476, 1995.

Pujol R, Puel JL, Gervais d'Aldin C, Eybalin M. Pathophysiology of the glutamatergic synapses in the cochlea. Acta Otolaryngol. (Stockh.) 113:330-334, 1993.

RAJAN R. Effect of electrical stimulation of the crossed olivocochlear bundle on temporary threshold shifts in auditory sensitivity. I. Dependence on electrical stimulation parameters. J. Neurophysiol. 60:549-568, 1988.

RoBERTSON D. Brainstem location of efferent neurones projecting to the guinea pig cochlea. Hear. Res. 20:79-84, 1985.

Robertson D, Anderson CJ, Cole KS. Segregation of efferent projections to different turns of the guinea pig cochlea. Hear. Res. 25:69-76, 1987.

Rooney BJ, Kavanagh GL, Kelly JB. Kainic acid lesions of the superior olivary complex: a horseradish peroxidase study of surviving brain-stem projections. J. Neurosci. Meth. 39:65-75, 1991.

Ruel J, Nouvian R, Gervais d’Aldin C, Pujol R, Eybalin M, Puel JL. Dopamine inhibition of auditory nerve activity in the adult mammalian cochlea. Eur. J. Neurosci. 14:977-986, 2001.

SAHLEY TL, NODAR RH. Improvement in auditory function following pentazocine suggests a role for dynorphins in auditory sensitivity. Ear Hear. 15:422-431, 1994.
Sahley TL, Kalish RB, Musiek FE, Hoffman DW. Effects of opioid be drugs on auditory evoked potentials suggest a role of lateral olivocochlear dynorphins in auditory function. Hear. Res. 55:133-142, 1991.

SAHLey TL, Nodar RH, Musiek FE. Blockade of opioid-induced changes in auditory function at the level of the cochlea. Ear Hear. 17:552-558, 1996a.

SAHLEy TL, Musiek FE, NodAR RH. Naloxone blockade of (-) pentazocine-induced changes in auditory function. Ear Hear. 17:341-353, 1996b.

SALLy SL, Kelly JB. Effects of superior olivary complex lesions on binaural responses in rat inferior colliculus. Brain Res. 572:5$18,1992$.

Sanes DH, Merickel M, Rubel EW. Evidence for an alteration of the tonotopic map in the gerbil cochlea during development. J. Comp. Neurol. 279:436-444, 1989.

Sommer I, Lingenhohl K, Friauf E. Principal cells of the rat medial nucleus of the trapezoid body: an intracellular in vivo study of their physiology and morphology. Exp. Brain Res. 95:223-239, 1993.

SPANGLER KM, WARR WB. Transneuronal changes in cochlear radial afferent fibers following destruction of lateral olivocochlear neurons. Soc. Neurosci. Abstr. 13:1258, 1987.

Sridhar TS, Liberman MC, Brown MC, Sewell WF. A novel cholinergic "slow effect" of efferent stimulation on cochlear potentials in the guinea pig. J. Neurosci. 15:3667-3678, 1995.

STOPP PE. The distribution of the olivocochlear bundle and its possible role in frequency/intensity coding. In: Hartmann R, Klinke R (eds) Hearing-Physiological Bases and Psychophysics. Springer, Berlin, 1983, pp 176-179.

STоре PE. The problem of obtaining reproducible quantitative data of the olivocochlear pathway as exemplified in the guinea pig. Eur. Arch. Otorhinolaryngol. 247:29-32, 1990.

Strutz J, Bielenberg K. Efferent acoustic neurons within the lateral superior olivary nucleus of the guinea pig. Brain Res. 299:174177, 1984.

Thorne PR, GAVIN JB. Changing relationships between structure and function in the cochlea during recovery from intense sound exposure. Ann. Otol. Rhinol. Laryngol. 94:81-86, 1985.

Tsuchitani C. Functional organization of lateral cell groups of cat superior olivary complex. J. Neurophysiol. 40:296-318, 1977.

Tsuchitani C, Boudreau JC. Single unit analysis of cat superior olive S segment with tonal stimuli. J. Neurophysiol. 29:684-697, 1966.

UnGan P, YaGCioglu S. Origin of the binaural interaction component in wave $\mathrm{P} 4$ of the short-latency auditory evoked potentials in the cat: evaluation of serial depth recordings from the brainstem. Hear. Res. 167:81-101, 2002.

WADA S, STARR A. Anatomical bases of binaural interaction in auditory brain-stem responses from guinea pig. Electroencephalogr. Clin. Neurophysiol. 72:535-544, 1989.

WARR WB. Organization of olivocochlear efferent systems in mammals. In: Webster DB, Popper AN, Fay RR (eds) Mammalian Auditory Pathway: Neuroanatomy. Little, Brown, Boston, 1992, pp 410-448.

WARR WB, Guinan JJ, White JS. Organization of efferent fibers: The lateral and medial olivocochlear systems. In: Altschule RA, Hoffman DW, Bobbin RP (eds) Neurobiology of Hearing: The Cochlea. Raven Press, New York, 1986, pp 333-348.

ZAAROOR M, STARr A. Auditory brain-stem evoked potentials in cat after kainic acid induced neuronal loss. I. Superior olivary complex. Electroencephalogr. Clin. Neurophysiol. 80:422-435, 1991.

Zheng XY, Henderson D, McFadden SL, Ding DL, Salvi RJ. Auditory nerve fiber responses following chronic cochlear de-efferentation. J. Comp. Neurol. 406:72-86, 1999. 